\title{
Trichogenic effect of topical ketoconazole versus minoxidil $2 \%$ in female pattern hair loss: a clinical and trichoscopic evaluation
}

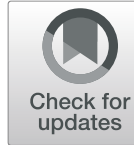

\author{
Ahmed El-Garf ${ }^{1}$, Mohamed Mohie ${ }^{2}$ and Eman Salah ${ }^{1 *}$ (D)
}

\begin{abstract}
Background: Female pattern hair loss (FPHL) is a common non-scaring alopecia. Topical minoxidil is the only approved treatment for FPHL; however, it has frequent side effects. Ketoconazole is an antifungal with anti-androgenic properties.

Methods: The aim of this work was to evaluate the safety and possible trichogenic effects of ketoconazole in FPHL. Patients were randomly assigned into Group A with 20 patients who received 2\% topical minoxidil solution and Group B involving 20 patients who were treated by $2 \%$ topical ketoconazole preparation. All patients were treated for 6 months and evaluated clinically plus via trichoscopy. Side effects were recorded, and patients' satisfaction was measured.

Results: Regarding hair growth, a significant difference was detected between baseline and at 4th and 6th months in Group A. While in Group B, the improvement was delayed until the 6th month. Only 10\% of Group B reported side effects. Patients' satisfaction did not differ between the two groups.

Conclusions: Topical ketoconazole mediates a trichogenic effect in FPHL with few side effects. However, ketoconazole showed a delayed improvement versus minoxidil at similar concentrations. Further studies should evaluate the efficacy of higher concentrations of ketoconazole solutions for FPHL which is a promising therapy.
\end{abstract}

Trial registration: IRB approval status: reviewed and approved by IRB of Faculty of Medicine, Zagazig University; approval no. \#3642

Keywords: Ketoconazole, Minoxidil, FPHL, Alopecia, Trichoscopy

\section{Introduction}

Since ancient times, there is no doubt that hair is one of the most determining features of a woman's appearance. Subsequently, female alopecia exhibits a devastating impact on quality of life (Tabolli et al. 2013). Female pattern hair loss (FPHL) is a non-scarring alopecia characterized by gradual and progressive miniaturization of hair follicles or terminal to villus hair shift (Trueb 2002). The disease can evolve early in young women before menarche or later in the 6th decade of life (Olsen et al. 2005). Clinically, FPHL patients show a reduced hair density over the crown and frontal scalp with preservation of anterior hairline or

\footnotetext{
* Correspondence: esmohamed@zu.edu.eg; connexin1980@yahoo.com 'Dermatology, Venereology \& Andrology Department, Faculty of Medicine, Zagazig University, Zagazig, Egypt

Full list of author information is available at the end of the article
}

what is commonly described as "Christmas tree" pattern (Blume-Peytavi et al. 2011a, b).

Initially, the Food and Drug Administration (FDA) has approved the twice-daily application of $1 \mathrm{ml}$ of topical minoxidil 2\% solution to treat FPHL (Blumeyer et al. 2011). Then in 2014, topical minoxidil at 5\% concentration was approved by both the FDA and Health Canada for FPHL (Kanti et al. 2018). The trichogenic effects of minoxidil can be explained by its ability to increase the anagen phase and decrease the telogen phase of the hair cycle, to promote the rate of hair growth and through its augmented proliferative and vasodilatory actions (Messenger and Rundegren 2004). However, topical minoxidil preparations are associated with frequent side effects as scalp pruritus or

(C) The Author(s). 2019 Open Access This article is distributed under the terms of the Creative Commons Attribution 4.0 International License (http://creativecommons.org/licenses/by/4.0/), which permits unrestricted use, distribution, and reproduction in any medium, provided you give appropriate credit to the original author(s) and the source, provide a link to the Creative Commons license, and indicate if changes were made. The Creative Commons Public Domain Dedication waiver (http://creativecommons.org/publicdomain/zero/1.0/) applies to the data made available in this article, unless otherwise stated. 
irritation and a bothersome facial hypertrichosis (Blume-Peytavi et al. 2011a, b).

Ketoconazole is an imidazole antifungal drug with anti-inflammatory actions due to its role against Malassezia infections (Van Cutsem et al. 1991). Additionally, ketoconazole has well-known anti-androgenic properties as it can inhibit and interfere with the process of steroidogenesis (Inui and Itami 2007). Accordingly, the topical application of ketoconazole may have a role in inhibiting the activity of androgen receptors and may be significant in controlling androgen-related hair loss. Therefore, Sonino et al. have suggested earlier a possible beneficial anti-androgenic effect of ketoconazole $2 \%$ shampoo in women with FPHL (Sonino et al. 1990).

In this work, we thought to investigate the safety and possible trichogenic effect of $2 \%$ topical ketoconazole preparation versus traditional $2 \%$ topical minoxidil solution in patients with FPHL.

\section{Patients and methods Ethical approvals}

The Institutional Review Board and ethical committees at Zagazig University Hospitals has approved this study (approval no. \#3642). All subjects gave a written informed consent before enrollment in this work.

\section{Setting}

This study was carried out at the Dermatology, Venereology \& Andrology Department and the compounding of ketoconazole microemulsion was prepared by the great help of our colleague at Pharmaceutics Department, Faculty of Pharmacy.

\section{Patients}

The study included a total of 40 patients with FPHL. Then, patients were randomly assigned into either Group A consisting of 20 patients who received 2\% topical minoxidil solution or Group B involving 20 patients who were treated by $2 \%$ topical ketoconazole preparation. Patients' inclusion criteria are as follow: females, age ranging from 18 to 65 years old, good general condition, clinically diagnosed FPHL with all grades of disease severity, and confirmed by a trichoscopic examination. Patients' exclusion criteria are as follows: pregnant, lactating, and patients who had used any hair-restoring treatment within the past 6 months.

\section{Methods}

All participants were subjected to detailed history and clinical examination to assess the baseline severity of hair loss according to Ludwig Scale with photodocumentation. Then, the 1st trichoscopic examination was performed to confirm the clinical diagnosis and to detect as well as to record the possible baseline trichoscopic findings with digital photographing using a connected smartphone device. The trichoscopic evaluation was performed via a polarized dermoscope (Dermlite, HÜD model) under a tenfold magnification and at both frontal as well as occipital scalp regions. Then, Group A patients were given a ready-made product of $2 \%$ minoxidil solution, while Group B patients were handled a compounded preparation containing $2 \%$ ketoconazole microemulsion. The bottles of the both medications were blinded, and the patients did not know which of the 2 solutions they are using. Every patient was instructed to apply $1 \mathrm{~mL}$ per day of the given medication to the scalp and for a 6-month treatment course.

The compounding of ketoconazole microemulsion solution $(2 \% \mathrm{w} / \mathrm{w})$ was prepared using oleic acid as oily phase, tween-80 as surfactant and propylene glycol and absolute ethanol as co-surfactants. Microemulsion was prepared by initially dissolving the required quantity of ketoconazole in oleic acid $(5 \% \mathrm{w} / \mathrm{w})$. Then, the mixture of surfactant and co-surfactants, composed of $15 \%$ tween $80,10 \%$ propylene glycol, and $40 \%$ ethanol, was added with continuous stirring on magnetic stirrer until a clear solution was obtained. Then water was added drop wise with continuous stirring. The formulation was equilibrated at ambient temperature for at least $48 \mathrm{~h}$ and examined for signs of turbidity or phase separation prior to clinical use (Amra and Momin 2019).

Table 1 Demographic and clinical data of the two studied groups

\begin{tabular}{|c|c|c|c|c|c|c|}
\hline Variable & \multicolumn{2}{|c|}{$\begin{array}{l}\text { Group A } \\
\text { Minoxidil 2\% } \\
(n=20)\end{array}$} & \multicolumn{2}{|c|}{$\begin{array}{l}\text { Group B } \\
\text { Ketoconazole 2\% } \\
(n=20)\end{array}$} & $\mathrm{MW}$ & $P$ \\
\hline \multicolumn{7}{|l|}{ Age (year) } \\
\hline Mean \pm SD & \multicolumn{2}{|c|}{$29.05 \pm 8.05$} & \multicolumn{2}{|c|}{$29.9 \pm 10.09$} & 0.08 & 0.94 \\
\hline Range & \multicolumn{2}{|c|}{$28(19-52)$} & \multicolumn{2}{|c|}{$27(19-50)$} & & NS \\
\hline Variable & No. & $\%$ & No. & $\%$ & $x^{2}$ & $P$ \\
\hline \multicolumn{7}{|l|}{ Family history } \\
\hline -ve & 7 & 35 & 5 & 25 & 0.48 & 0.49 \\
\hline +ve & 13 & 65 & 15 & 75 & & NS \\
\hline Variable & & & & & $\mathrm{MW}$ & $P$ \\
\hline \multicolumn{7}{|l|}{ Disease duration (year) } \\
\hline Mean \pm SD & \multicolumn{2}{|c|}{$2.75 \pm 1.01$} & \multicolumn{2}{|c|}{$2.45 \pm 1.15$} & 0.89 & 0.37 \\
\hline Median (range) & \multicolumn{2}{|c|}{$3(1-5)$} & \multicolumn{2}{|c|}{$2.5(1-5)$} & & NS \\
\hline Variable & No. & $\%$ & No. & $\%$ & $x^{2}$ & P \\
\hline \multicolumn{7}{|l|}{ Previous treatments } \\
\hline No & 19 & 95 & 17 & 85 & & \\
\hline Platelet-rich plasma & 1 & 5 & 1 & 5 & 2.11 & 0.35 \\
\hline Minoxidil 5\% & 0 & 0 & 2 & 10 & & NS \\
\hline
\end{tabular}

SD standard deviation, MW Mann-Whitney test, $\chi^{2}$ Chi square test, NS non-significant $(P>0.05)$ 
All patients were subjected to follow-up visits every 2 month for 6 months. At each visit, re-examination was performed including the changes in Ludwig score and trichoscopic signs. Additionally, reporting of any side effects was done and all patients were asked to rate their satisfaction level about the used treatment at the end of the study.

\section{Statistical analysis}

The collected data were computerized and statistically analyzed using SPSS program (Statistical Package for Social Science) version 18.0. Qualitative data were represented as frequencies and relative percentages. Chi square test was used to calculate difference between qualitative variables. Quantitative data were expressed as mean $\pm \mathrm{SD}$ (standard deviation). McNemar test and Mann-Whitney test were also used. Mann-Whitney test was used to calculate difference between quantitative variables. McNemar test was used to find difference between qualitative data in the same group at different time. $P$ value $<0.05$ was considered statistically significant.

\section{Results}

The present study included 40 patients with FPHL who were randomly and equally assigned into one of two groups: Group A is the minoxidil group and Group B is the ketoconazole group. The minoxidil group involved 20 patients with a mean age of $29.05 \pm 8.05$ years while the ketoconazole group included 20 patients with a mean of $29.9 \pm 10.09$ years as illustrated in Table 1 . There was no statistically significant difference between the two studied groups regarding age, family history of FPHL, disease duration, and previously used as shown in Table 1 .

Regarding the changes in Ludwig score and disease severity among the two studied groups during the follow-up visits there were statistical significance differences between the two studied groups at baseline; then, after 2 months and at the end of the 6th month (Table 2 and Fig. 1). Furthermore, within each group, there was a highly significant difference between baseline severity and at both the 4th and 6th month in Group A or the minoxidil group. On the other hand, the ketoconazole group or Group B showed a delayed therapeutic response with statistically significance difference between baseline disease severity and only at the end of the 6th month (Table 2 and Fig. 1).

Table 2 Ludwig scale changes in the two studied groups

\begin{tabular}{|c|c|c|c|c|c|c|}
\hline \multirow[t]{2}{*}{ Variable } & \multicolumn{2}{|c|}{$\begin{array}{l}\text { Group A } \\
\text { Minoxidil 2\% } \\
(n=20)\end{array}$} & \multicolumn{2}{|c|}{$\begin{array}{l}\text { Group B } \\
\text { Ketoconazole 2\% } \\
(n=20)\end{array}$} & \multirow[t]{2}{*}{$x^{2}$} & \multirow[t]{2}{*}{$P$} \\
\hline & No. & $\%$ & No. & $\%$ & & \\
\hline \multicolumn{7}{|c|}{ Ludwig scale: (baseline) } \\
\hline Stage I & 0 & 0 & 8 & 40 & \multirow[t]{3}{*}{10.67} & \multirow[t]{3}{*}{$0.005^{* *}$} \\
\hline Stage ॥ & 16 & 80 & 8 & 40 & & \\
\hline Stage III & 4 & 20 & 4 & 20 & & \\
\hline \multicolumn{7}{|c|}{ Ludwig scale: (after 2 months) } \\
\hline Stage I & 0 & 0 & 8 & 40 & \multirow[t]{3}{*}{10.67} & \multirow[t]{3}{*}{$0.005^{* *}$} \\
\hline Stage ॥ & 16 & 80 & 8 & 40 & & \\
\hline Stage III & 4 & 20 & 4 & 20 & & \\
\hline \multicolumn{7}{|c|}{ Ludwig scale: (after 4 months) } \\
\hline Stage I & 16 & 80 & 12 & 60 & \multirow[t]{3}{*}{4.57} & \multirow[t]{3}{*}{$0.10 \mathrm{NS}$} \\
\hline Stage ॥ & 4 & 20 & 4 & 20 & & \\
\hline Stage III & 0 & 0 & 4 & 20 & & \\
\hline \multicolumn{7}{|c|}{ Ludwig scale: (after 6 months) } \\
\hline Normal & 4 & 20 & 8 & 40 & \multirow[t]{6}{*}{8} & \multirow[t]{6}{*}{$0.02^{*}$} \\
\hline Stage I & 16 & 80 & 8 & 40 & & \\
\hline Stage II & 0 & 0 & 4 & 20 & & \\
\hline$P^{1 \#}$ & $1 \mathrm{NS}$ & & $1 \mathrm{NS}$ & & & \\
\hline$p^{2 \#}$ & $<0.001^{* *}$ & & 0.13 NS & & & \\
\hline$p^{3 \#}$ & $<0.001^{* *}$ & & $0.02^{*}$ & & & \\
\hline
\end{tabular}

"McNemar test

*Significant $(P<0.05)$

**Highly significant $(P<0.01)$

$X^{2}$ Chi square test, $P^{1}$ baseline versus after 2 months, $P^{2}$ baseline versus after 4 months, $P^{3}$ baseline versus after 6 months, NS non-significan0t $(P>0.05)$ 


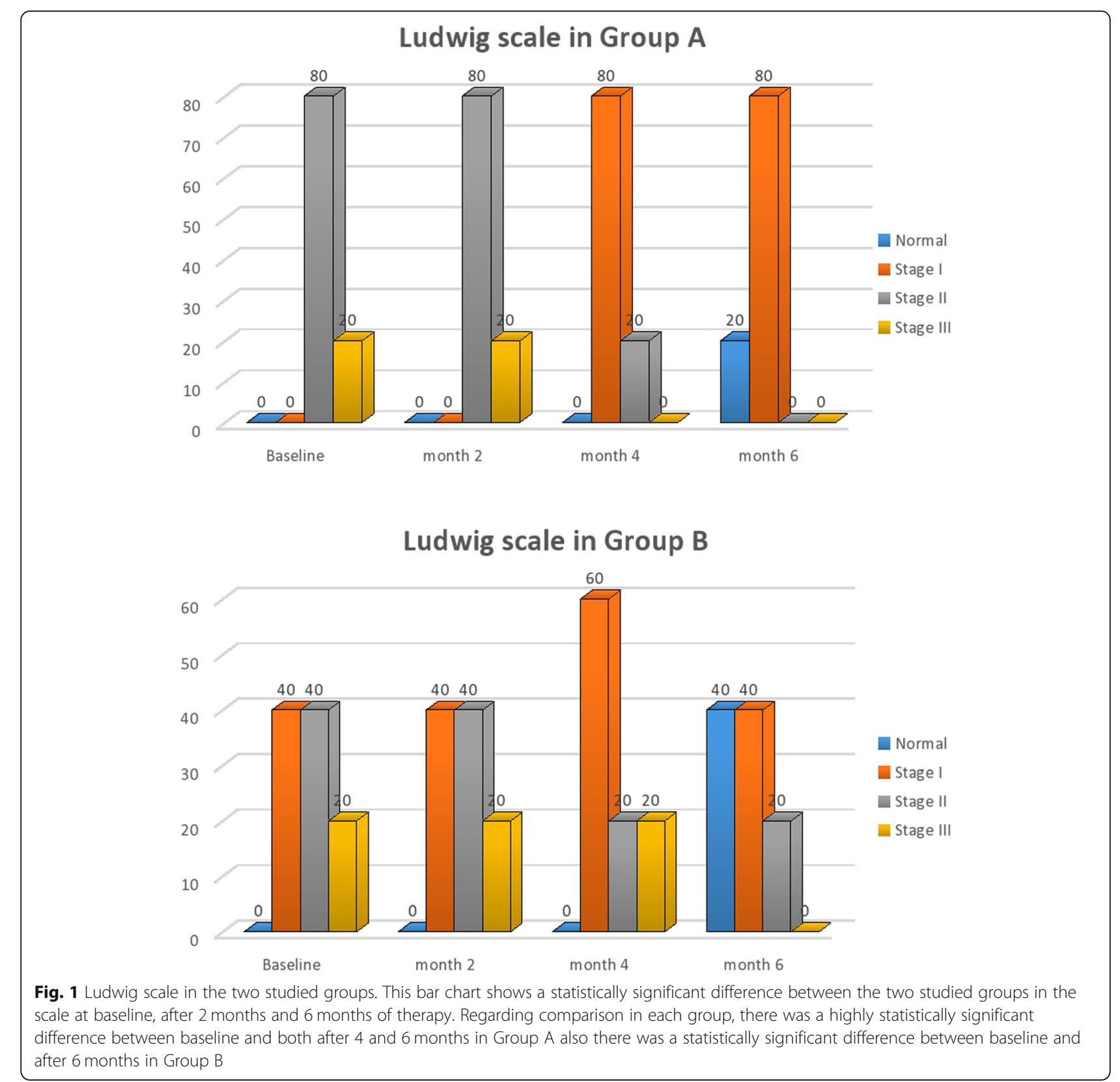

Additionally, the trichoscopic examination evaluated the following main signs of FPHL including hair shaft thickness heterogeneity, brown peripilar sign, focal atrichia, and yellow dots. There was a statistically significant difference between the two studied groups only regarding the brown peripilar sign at the 4th month of therapy. However, within each group there was a highly significant difference between baseline trichoscopic findings and at the 4th and 6th month in Group A as well as in Group B Table 3. Figures 2 and 3 demonstrate an example of the clinical and trichoscopic findings in the minoxidil and ketoconazole (KCZ) groups.
The frequency of treatment-related side effects was more reported in the minoxidil group (55\%) than in the ketoconazole group (10\%) as shown in Table 4. Finally, the levels of patients' satisfaction did not show a statistically significant difference between the two studied groups (Table 5).

\section{Discussion}

Female pattern hair loss (FPHL) is the most common type of hair loss in women. Genetics as well as hormonal factors are involved in pathogenesis of FPHL. The conversion of testosterone into dihydrotestosterone in the hair follicles is supposed to initiate terminal to vellus 
Table 3 Trichoscopic findings in the two studied groups

\begin{tabular}{|c|c|c|c|c|c|c|}
\hline \multirow[t]{2}{*}{ Variable } & \multicolumn{2}{|c|}{$\begin{array}{l}\text { Group A } \\
\text { Minoxidil 2\% } \\
(n=20)\end{array}$} & \multicolumn{2}{|c|}{$\begin{array}{l}\text { Group B } \\
\text { Ketoconazole 2\% } \\
(n=20)\end{array}$} & \multirow[t]{2}{*}{$x^{2}$} & \multirow[t]{2}{*}{$P$} \\
\hline & No. & $\%$ & No. & $\%$ & & \\
\hline \multicolumn{7}{|l|}{ Trichoscopic findings: (baseline) } \\
\hline Hair shaft thickness heterogeneity & 20 & 100 & 20 & 100 & 0 & $1 \mathrm{NS}$ \\
\hline Brown peripilar sign & 20 & 100 & 20 & 100 & 0 & $1 \mathrm{NS}$ \\
\hline Focal atrichia & 15 & 75 & 15 & 75 & 0 & $1 \mathrm{NS}$ \\
\hline Yellow dots & 4 & 20 & 2 & 10 & 0.78 & 0.38 NS \\
\hline \multicolumn{7}{|l|}{ Trichoscopic findings: (after 2 months) } \\
\hline Hair shaft thickness heterogeneity & 20 & 100 & 20 & 100 & 0 & $1 \mathrm{NS}$ \\
\hline Brown peripilar sign & 16 & 80 & 12 & 60 & 1.91 & $0.17 \mathrm{NS}$ \\
\hline Focal atrichia & 7 & 35 & 7 & 35 & 0 & $1 \mathrm{NS}$ \\
\hline Yellow dots & 1 & 5 & 0 & 0 & 0.93 & 0.34 NS \\
\hline \multicolumn{7}{|l|}{ Trichoscopic findings: (after 4 months) } \\
\hline Hair shaft thickness heterogeneity & 20 & 100 & 20 & 100 & 0 & $1 \mathrm{NS}$ \\
\hline Brown peripilar sign & 9 & 45 & 1 & 5 & 10.51 & $<0.001^{* *}$ \\
\hline Focal atrichia & 2 & 10 & 4 & 20 & 0.78 & 0.38 NS \\
\hline Yellow dots & 0 & 0 & 0 & 0 & - & - \\
\hline \multicolumn{7}{|l|}{ Trichoscopic findings: (after 6 months) } \\
\hline Normal & 4 & 20 & 8 & 40 & 1.38 & 0.24 NS \\
\hline Hair shaft thickness heterogeneity & 16 & 80 & 12 & 60 & 1.91 & $0.17 \mathrm{NS}$ \\
\hline Brown peripilar sign & 1 & 5 & 0 & 0 & 0.93 & 0.34 NS \\
\hline Focal atrichia & 0 & 0 & 0 & 0 & - & - \\
\hline Yellow dots & 0 & 0 & 0 & 0 & - & - \\
\hline$P^{1 \#}$ & \multicolumn{2}{|c|}{0.99 NS } & \multicolumn{4}{|c|}{$0.06 \mathrm{NS}$} \\
\hline$P^{2 \#}$ & \multicolumn{2}{|c|}{$0.008^{* *}$} & \multicolumn{4}{|c|}{$<0.001^{* *}$} \\
\hline$P^{3 \#}$ & \multicolumn{2}{|c|}{$<0.001^{* *}$} & \multicolumn{4}{|c|}{$<0.001^{* *}$} \\
\hline
\end{tabular}

\#McNemar test

**Highly significant $(P<0.01)$

$X^{2}$ Chi square test, NS non-significant $(P>0.05), P^{1}$ baseline versus after 2 months, $P^{2}$ baseline versus after 4 months, $P^{3}$ baseline versus after 6 months

hair shift or miniaturization (Price 2003). Furthermore, the role of microinflammation with pro-inflammatory mediators and cytokines have been suggested and linked to failure of minoxidil therapy in some patients (Mahé et al. 2000).

In the present work, topical $2 \% \mathrm{KCZ}$ microemulsion achieved a successful hair stimulating effects comparable to traditional $2 \%$ topical minoxidil in patients with FPHL. Up to our knowledge, this is the first study to evaluate the efficacy and safety of topical $\mathrm{KCZ}$ as a microemulsion in FPHL patients in comparison to topical minoxidil.

Earlier to our study, Pierard-Franchimont et al. (1998) found that hair density and proportion of anagen follicles were much improved by the long-term use of a $2 \%$ KCZ-containing shampoo in male pattern hair loss (MPHL) without any associated seborrheic dermatitis or dandruff. Furthermore, they have also reported similar improvement levels to topical minoxidil at $2 \%$ concentration (Pierard-Franchimont et al. 1998). Additionally, a regimen combining $2 \% \mathrm{KCZ}$ shampoo to oral finasteride was found to induce hair re-growth in MPHL (Khandpur et al. 2002).

Also, in animal studies, topical application of $2 \%$ $\mathrm{KCZ}$ solution stimulated the telogen-to-anagen hair conversion and positive hair growth in $\mathrm{C} 3 \mathrm{H} / \mathrm{HeN}$ mice (Jiang et al. 2005). Subsequently in 2014, Aldhalimi et al. have confirmed the significant trichogenic effects of topical KCZ in mice at the histopathological level with increased follicular diameter and new hair growth (Aldhalimi et al. 2014).

The most common proposed mechanism of action for topical KCZ in androgenetic alopecia (AGA) is via its known anti-androgenic properties (Hugo Perez 2004). However, Aldhalimi et al. demonstrated that it was also effective on the androgen-insensitive coat hairs of mice 

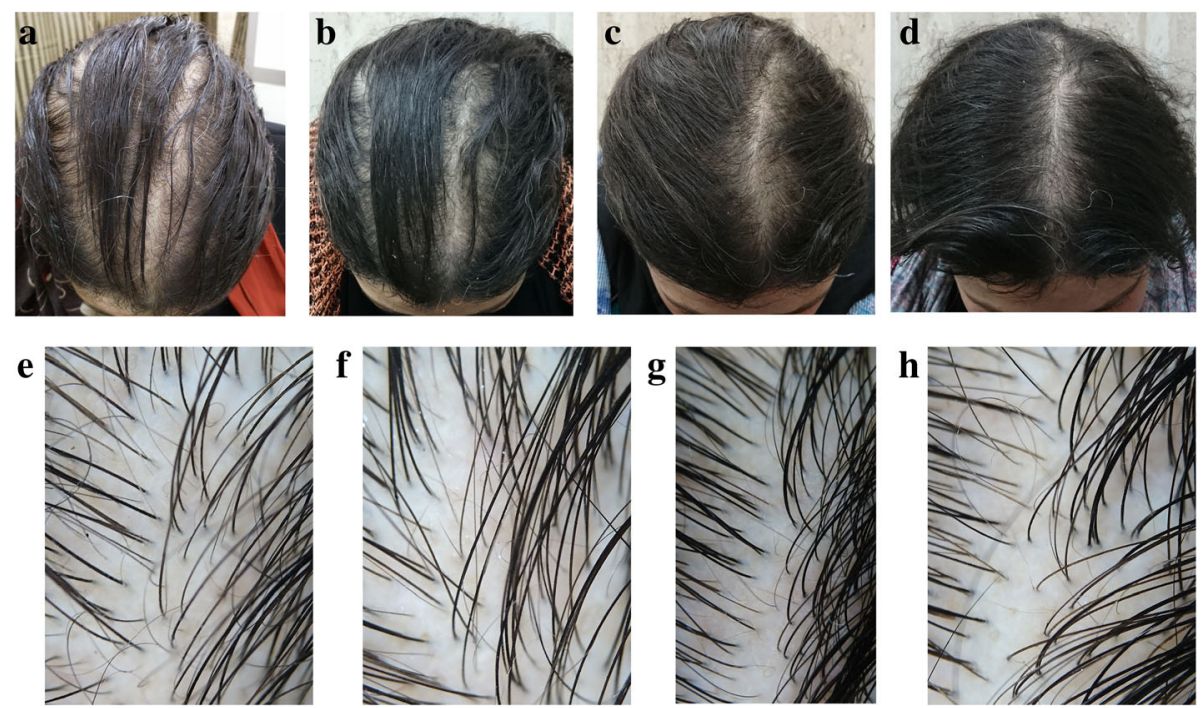

Fig. 2 Example of the clinical and trichoscopic findings in the minoxidil group. At baseline (a, e), after 2 months $(\mathbf{b}, \mathbf{f})$, after 4 months $(\mathbf{c}, \mathbf{g})$, and after 6 months $(\mathbf{d}, \mathbf{h})$

(Aldhalimi et al. 2014). This finding indicates that topical KCZ may act through androgen-dependent as well as androgen-independent pathway, which warrants further investigations. Another possible explanation for the ability of topical KCZ to improve our patients with FPHL is its anti-inflammatory effect through the inhibition of 5-lipoxygenase activity and leukotrienes production (Beetens et al. 1986).

Regarding the results of trichoscopy in our patients, there was a statistically significant difference between the two studied groups only regarding the "brown peripilar sign" at the 4th month of therapy. The "brown peripilar sign" is characterized by a brown halo around the emergent hair shaft with a diameter of approximately $1 \mathrm{~mm}$. This sign is linked to superficial perifollicular inflammatory infiltrate mainly of lymphocytes (Deloche et al. 2004). So, this difference may be linked to the antiinflammatory actions of KCZ (Jiang et al. 2005). On the other hand, within each studied group, there was a highly significant difference between baseline trichoscopic findings and at the 4th and 6th month in the minoxidil group as well as in the $\mathrm{KCZ}$ group.

The presented work revealed that topical $\mathrm{KCZ}$ showed a delayed clinical therapeutic response with statistically

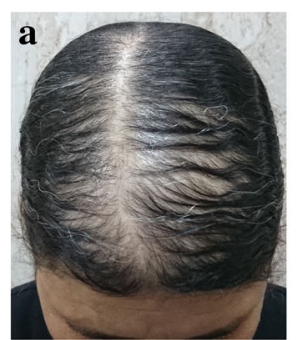

e

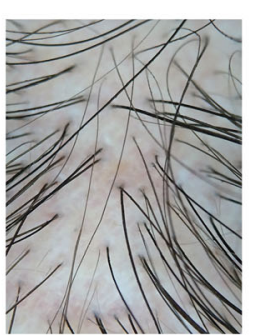

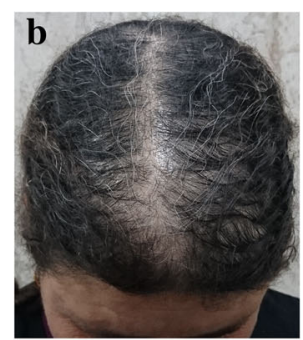

$\mathbf{f}$

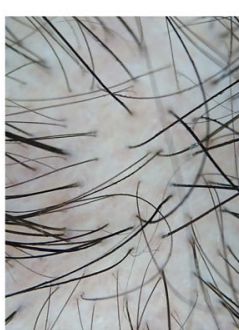

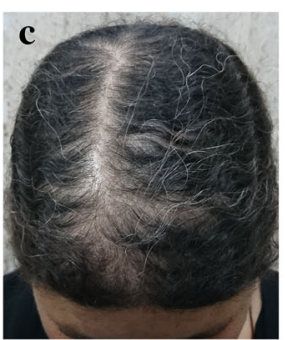

g

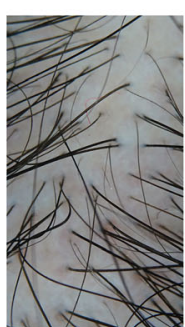

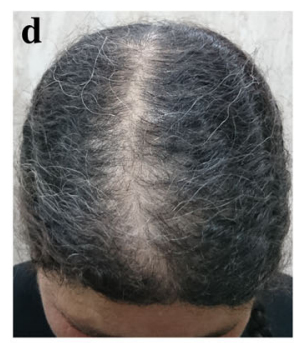

h

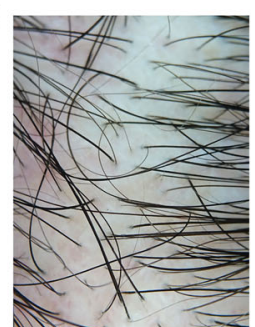

Fig. 3 Example of the clinical and trichoscopic findings in the ketoconazole group. At baseline (a, e), after 2 months (b, f), after 4 months (c, $\mathbf{g}$ ) and after 6 months (d, h) 
Table 4 Treatment associated side effects in the two studied groups

\begin{tabular}{|c|c|c|c|c|c|c|}
\hline \multirow[t]{2}{*}{ Variable } & \multicolumn{2}{|c|}{$\begin{array}{l}\text { Group A } \\
\text { Minoxidil 2\% } \\
(n=20)\end{array}$} & \multicolumn{2}{|c|}{$\begin{array}{l}\text { Group B } \\
\text { Ketoconazole 2\% } \\
(n=20)\end{array}$} & \multirow[t]{2}{*}{$x^{2}$} & \multirow[t]{2}{*}{$P$} \\
\hline & No. & $\%$ & No. & $\%$ & & \\
\hline \multicolumn{7}{|l|}{ Side effects } \\
\hline None & 9 & 45 & 18 & 90 & 13.33 & $0.004^{* *}$ \\
\hline Dermatitis & 1 & 5 & 2 & 10 & & \\
\hline Hypertrichosis & 8 & 40 & 0 & 0 & & \\
\hline Both & 2 & 10 & 0 & 0 & & \\
\hline
\end{tabular}

**Highly significant $(P<0.01)$

$X^{2}$ Chi square test

significant difference between baseline disease severity and only at the end of the 6th month according to Ludwig scale. In contrast, topical minoxidil at similar concentration started to show earlier clinical improvement at the 4th month of treatment. This means that the rate of patient improvement was similar in both groups under trichoscopy; however, clinically, the minoxidil group showed earlier improvement. Perhaps a faster clinical response needs higher concentration of $\mathrm{KCZ}$, which needs further studies.

Topical minoxidil is the FDA approved treatment for FPHL; however, it has no anti-androgenic effects (Kanti et al. 2018). Minoxidil works through its metabolite namely "minoxidil sulphate" to mediate augmented proliferative and vasodilatory actions. This in turn is expected to increase the anagen phase and decrease the telogen phase of the hair cycle to promote new hair growth (Messenger and Rundegren 2004). Unfortunately, topical minoxidil application has a narrow safety margin with bothering side effects including scalp contact dermatitis, headaches, and facial hypertrichosis especially in females (Hagemann et al. 2005; Blume-Peytavi et al. 2011a, b; La Placa et al. 2015). In agreement with this, the frequency of treatment-related side effects was 55\% with the minoxidil group versus just $10 \%$ in the $\mathrm{KCZ}$ group, in the presented work. It seems that the main advantage of topical $\mathrm{KCZ}$ over topical minoxidil is the true paucity of side effects. In fact, in 2013, the FDA has reported that topical ketoconazole formulations have not

Table 5 Patient satisfaction levels in the two studied groups

\begin{tabular}{|c|c|c|c|c|c|c|}
\hline \multirow[t]{2}{*}{ Variable } & \multicolumn{2}{|c|}{$\begin{array}{l}\text { Group A } \\
\text { Minoxidil 2\% } \\
(n=20)\end{array}$} & \multicolumn{2}{|c|}{$\begin{array}{l}\text { Group B } \\
\text { Ketoconazole } \\
2 \%(n=20)\end{array}$} & \multirow[t]{2}{*}{$x^{2}$} & \multirow[t]{2}{*}{$P$} \\
\hline & No & $\%$ & No & $\%$ & & \\
\hline \multicolumn{7}{|l|}{ Satisfaction level } \\
\hline Not satisfied & 1 & 5 & 1 & 5 & \multirow[t]{3}{*}{0} & 1 \\
\hline Satisfied & 15 & 75 & 15 & 75 & & \\
\hline Very satisfied & 4 & 20 & 4 & 20 & & \\
\hline
\end{tabular}

$X^{2}$ Chi square test, NS non-significant $(P>0.05)$ been associated with adrenal problems, liver damage, or drug interactions (Food and Drug Administration 2013). Also, the European Medicines Agency recommendations' is to use topical KCZ preparations safely as the likely absorbed amounts throughout the body are negligible (European Medicines Agency 2013).

Finally, the levels of patients' satisfaction did not show a statistically significant difference between the two studied groups which indicates that the results of topical $\mathrm{KCZ}$ are very much appreciated by patients like topical minoxidil. However, KCZ emulsion is superior to minoxidil solution as it almost lacks side effects. It would be interesting to investigate if combining topical minoxidil with its vasodilating actions to topical $\mathrm{KCZ}$ with its antiandrogenic and anti-inflammatory effects would target the pathogenesis of FPHL in a better way than either treatment separately. In agreement with this possibility, Singh et al. (2016) have already prepared an emulsionbased gel containing $\mathrm{KCZ}$ and minoxidil for the treatment of dandruff and associated hair loss based on antiinflammatory and anti-androgenic properties of $\mathrm{KCZ}$ (Singh et al. 2016).

\section{Conclusions and recommendations}

Topical KCZ microemulsion can induce a significant trichogenic effect in FPHL with a high safety profile in contrast to traditional minoxidil therapy. However, the clinical therapeutic response with topical $2 \% \mathrm{KCZ}$ microemulsion is slower than topical minoxidil at similar concentrations. We highly recommend further studies to evaluate the efficacy of $\mathrm{KCZ}$ at higher concentrations and different formulations for FPHL patients. Topical KCZ could be a new emerging, effective, and safe therapy for hair loss.

\section{Abbreviations}

AGA: Androgentic alopecia; FDA: Food and Drug Administration; FPHL: Female pattern hair loss; KCZ: Ketoconazole; MPHL: Male pattern hair loss

\section{Acknowledgements}

We would like to thank Dr. Mahmoud Mokhtar Ibrahim, Assistant Professor of Pharmaceutics, Faculty of Pharmacy, Zagazig University, Egypt, for preparing the KCZ microemulsion compound and for his valuable help.

\section{Authors' contributions}

ES is the leader of this work and the main writer of the manuscript. Otherwise, all authors contributed to this work equally. All authors read and approved the final manuscript.

Funding

None

Availability of data and materials

Not applicable

Ethics approval and consent to participate

The Institutional Review Board and ethical committees approved this study (approval no. \#3642). All subjects gave a written informed consent before enrollment in this work. 


\section{Consent for publication}

Written informed consent was obtained from the patients for publication of their individual details and accompanying images in this manuscript. The consent form is held by the authors and is available for review by the Editorin-Chief.

\section{Competing interests}

The authors declare that they have no competing interests.

\section{Author details}

'Dermatology, Venereology \& Andrology Department, Faculty of Medicine, Zagazig University, Zagazig, Egypt. ${ }^{2}$ Faculty of Medicine, Zagazig University, Zagazig, Egypt.

Received: 5 August 2019 Accepted: 9 October 2019

Published online: 05 December 2019

\section{References}

Aldhalimi MA, Hadi NR, Ghafil FA. Promotive effect of topical ketoconazole, minoxidil, and minoxidil with tretinoin on hair growth in male mice. ISRN Pharmacol. 2014;2014:575423.

Amra K and Momin M (2019): Formulation evaluation of ketoconazole microemulsion-loaded hydrogel with nigella oil as a penetration enhancer. J Cosmet Dermatol. 2019. doi: https://doi.org/10.1111/jocd.12945.

Beetens JR, Loots W, Somers Y, et al. Ketoconazole inhibits the biosynthesis of leukotrienes in vitro and in vivo. Biochem Pharmacol. 1986;35(6):883-91.

Blume-Peytavi U, Blumeyer A, Tosti A, et al. S1 guideline for diagnostic evaluation in androgenetic alopecia in men, women and adolescents. $\mathrm{Br} J$ Dermatol. 2011a;164(1):5-15.

Blume-Peytavi U, Hillmann K, Dietz E, et al. A randomized, single-blind trial of 5\% minoxidil foam once daily versus $2 \%$ minoxidil solution twice daily in the treatment of androgenetic alopecia in women. J Am Acad Dermatol. 2011 b; 65(6):1126-34.

Blumeyer A, Tosti A, Messenger A, et al. Evidence-based (S3) guideline for the treatment of androgenetic alopecia in women and in men. J Dtsch Dermatol Ges. 2011;9(s6).

Deloche C, Lacharrière OD, Misciali C, et al. Histological features of peripilar signs associated with androgenetic alopecia. Arch Dermatol Res. 2004; 295(10):422-8

European Medicines Agency (2013): European Medicines Agency recommends suspension of marketing authorisations for oral ketoconazole. https:/www. ema.europa.eu/en/news/european-medicines-agency-recommendssuspension-marketing-authorisations-oral-ketoconazole.

Food and Drug Administration. (2013): FDA limits usage of Nizoral (ketoconazole) oral tablets due to potentially fatal liver injury and risk of drug interactions and adrenal gland problems. https:/www.fda.gov/drugs/drug-safety-andavailability/fda-drug-safety-communication-fda-limits-usage-nizoralketoconazole-oral-tablets-due-potentially. .

Hagemann T, Schlütter-Böhmer B, Allam JP, Bieber T, Novak N. Positive lymphocyte transformation test in a patient with allergic contact dermatitis of the scalp after short-term use of topical minoxidil solution. Contact Dermatitis. 2005;53(1):53-5.

Hugo Perez BS. (2004): Ketocazole as an adjunct to finasteride in the treatment of androgenetic alopecia in men. Med Hypotheses. 2004;62(1):112-5.

Inui S, Itami S. Reversal of androgenetic alopecia by topical ketoconzole: relevance of anti-androgenic activity. J Dermatol Sci. 2007;45(1):66-8.

Jiang J, Tsuboi R, Kojima Y, et al. Topical application of ketoconazole stimulates hair growth in C3H/HeN mice. J Dermatol. 2005;32(4):243-7.

Kanti V, Messenger A, Dobos G, et al. Evidence based (S3) guidelines for the treatment of androgenetic alopecia in women and in men. J Eur Acad Dermatol Venereol. 2018;32:11-22.

Khandpur S, Suman M, Reddy BS. Comparative efficacy of various treatment regimens for androgenetic alopecia in men. J Dermatol. 2002;29(8):489-98.

La Placa M, Balestri R, Bardazzi F, et al. Scalp psoriasiform contact dermatitis with acute telogen effluvium due to topical minoxidil treatment. Skin appendage disor. 2015;1(3):141-3.

Mahé YF, Michelet JF, Billoni N, et al. Androgenetic alopecia and microinflammation. Int J Dermatol. 2000;39(8):576-84.

Messenger AG, Rundegren J. Minoxidil: mechanisms of action on hair growth. $\mathrm{Br}$ J Dermatol. 2004;150(2):186-94.
Olsen EA, Messenger AG, Shapiro J, et al. Evaluation and treatment of male and female pattern hair loss. J Am Acad Dermatol. 2005;52(2):301-11.

Pierard-Franchimont C, De Doncker P, Cauwenbergh G, et al. Ketoconazole shampoo: effect of long-term use in androgenic alopecia. Dermatology. 1998;196(4):474-7.

Price VH. Androgenetic alopecia in women. J Investig Dermatol Symp Proc. 2003;8(1):24-7.

Singh M, Hariharan AG, Sudhakar CK, et al. A new perspective for the treatment of dandruff \& associated alopecia with emulsion based gel containing ketoconazole and minoxidil. IntJ Pharm Sci Res. 2016;46:3899-06. https://doi. org/10.13040/IJPSR.0975-8232.7(9).3899-06.

Sonino N, Scaroni C, Biason A, et al. Low-dose ketoconazole treatment in hirsute women. J Endocrinol Investig. 1990;13(1):35-40.

Tabolli S, Sampogna F, Di Pietro C, et al. Health status, coping strategies, and alexithymia in subjects with androgenetic alopecia: a questionnaire study. Am J Clin Dermatol. 2013;14(2):139-45.

Trueb RM. Molecular mechanisms of androgenetic alopecia. Exp Gerontol. 2002; 37(8):981-90

Van Cutsem J, Van Gerven F, Cauwenbergh G, et al. The antiinflammatory effects of ketoconazole: a comparative study with hydrocortisone acetate in a model using living and killed Staphylococcus aureus on the skin of Guinea pigs. J Am Acad Dermatol. 1991;25(2):257-61.

\section{Publisher's Note}

Springer Nature remains neutral with regard to jurisdictional claims in published maps and institutional affiliations.
Ready to submit your research? Choose BMC and benefit from:

- fast, convenient online submission

- thorough peer review by experienced researchers in your field

- rapid publication on acceptance

- support for research data, including large and complex data types

- gold Open Access which fosters wider collaboration and increased citations

- maximum visibility for your research: over $100 \mathrm{M}$ website views per year

At BMC, research is always in progress.

Learn more biomedcentral.com/submissions 